\title{
The Study on Single-Phase Adaptive Reclosure of Transmission Lines with Series Capacitance
}

\author{
Liu Qiao ${ }^{1, *}$, Yao Tian-liang ${ }^{1}$, Liang Zhen-feng ${ }^{2}$, Yang Xiao-ping ${ }^{2}$ \\ ${ }^{1}$ China Energy Engineering Group Gansu Electric Power Design Institute CO.,LTD,Lan Zhou,China \\ ${ }^{2}$ Institute of Resources and hydro-electric Engineering, Xi 'An University of Technology Xi 'An, \\ China \\ aemail: liuqiao1121@qq.com \\ *Corresponding Author
}

Keywords: Power system, Series compensation, Recovery voltage, Least square fitting, Single-phase adaptive reclosure.

\begin{abstract}
To solve the problem of single-phase adaptive reclose in line with series compensation, this paper proposes a criterion using the different frequency components belonged to the recovery voltage to defect transient faults and permanent faults. Firstly, this paper analysis the frequency characteristics after fault-phase circuit breaker tripped in single-phase ground fault, establishes the recovery voltage identification model including the DC component and each component. When single-phase-to-ground fault occurs and both sides of the circuit breaker open, the recovery voltage as a known quantity, each frequency component is obtained by least square fitting. The amplitudes of various frequency components are adopted to distinguish the permanent faults from transient faults. Through theoretical analysis and PSCAD simulation show that the criterion is correct and effective and can detect the nature of single-phase fault quickly.
\end{abstract}

\section{Introduction}

Automatic reclosing is widely used in transmission lines, but the failure may cause impact on the system again, will shorten the service life of circuit breaker and electric equipment. Therefore, adaptive reclose widely research that can improve the success rate ${ }^{[1]}$.

In order to limit EHV transmission line power frequency overvoltage, the shunt reactors are usually installed on both ends of the line or end. In order to improve line transmission ability and system operation stability ${ }^{[2]}$, the series compensation capacitance often is installed in the limit/ehv transmission line. The existence of the low frequency component increases the difficulty of the fault judging. Series compensation device itself protection operation, on the other hand, will bypass the series capacitors, also increase the difficulty of the fault judging.

Firstly, this paper analyzes and calculates the frequency of recovery voltage on the transmission line with series compensation capacitors and shunt reactor, establishes the recovery voltage model that contains aperiodic component, power frequency component and free oscillation component. This paper uses least-squares draft count to solve each frequency component. By comparing the difference 
between the various frequency identify the nature of the fault. Simulation results indicate the effectiveness of the proposed algorithm.

\section{Series compensation capacitor and the protection of MOV}

Figure 1 is a transmission line series compensation capacitor device wiring diagram. $\mathrm{C}$ is series capacitor banks, MOV is Zinc oxide varistor. $\mathrm{G}$ is discharge gap, QF is bypass breaker, using for arc extinguishing of discharge gap $\mathrm{G}$ and investment and return of the series capacitor.

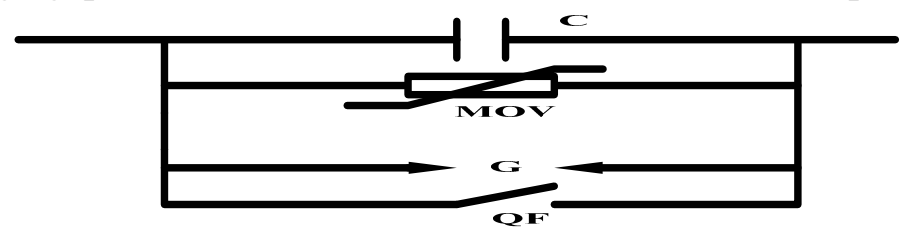

Fig.1. Series capacitor compensation device

\section{Transient recovery voltage characteristics and the influence of series compensation}

\subsection{Simulation model}

The recovery voltage characteristics of transient fault and permanent fault is demonstrated in a $500 \mathrm{kV}$ translation line model.

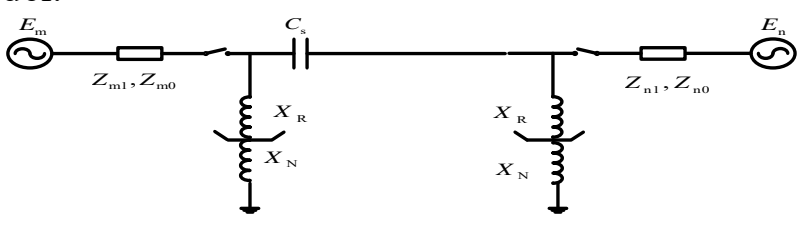

Fig.2. The model of $500 \mathrm{kV}$ translation line

In Fig. 2 above, the positive sequence resistance $\left(R_{1}\right)$ is $0.347 \Omega / \mathrm{km}$, positive sequence capacitance $\left(\mathrm{C}_{1}\right)$ is $0.00868 \mu \mathrm{F} / \mathrm{km}$, positive sequence inductance $\left(\mathrm{L}_{1}\right)$ is $1.343 \mathrm{mH} / \mathrm{km}$, zero-sequence resistance $\left(\mathrm{R}_{0}\right)$ is $0.30002 \Omega / \mathrm{km}$, zero-sequence inductance $\left(\mathrm{L}_{0}\right)$ is $3.638 \mathrm{mH} / \mathrm{km}$, zero-sequence capacitance $\left(\mathrm{C}_{0}\right)$ is $0.00617 \mu \mathrm{F} / \mathrm{km}$. The parameters in $\mathrm{M}$ side: $\mathrm{Z}_{\mathrm{m} 1}=6.139+\mathrm{j} 529.8 \Omega, \mathrm{Z}_{\mathrm{m} 0}=\mathrm{j} 130.6 \Omega$. The parameters in $\mathrm{N}$ side: $\mathrm{Z}_{\mathrm{n} 1}=17.56+\mathrm{j} 46.11 \Omega, \mathrm{Z}_{\mathrm{n} 0}=1.6+\mathrm{j} 65.13 \Omega$. The parameter of the reactors which paralleled in the circuit is equal to that in Neutral point is: $X_{R}=1708.16 \Omega, X_{N}=569.39 \Omega$. The length of transmission line is $300 \mathrm{~km}$. $\mathrm{C}_{\mathrm{s}}$ is the series compensation capacitor and the series compensation degree is $30 \%$.

\subsection{The characteristic of recovery voltage in normal operation}

(1) At single-phase ground fault, breaker tripped at the phase which is fault, the equivalent circuit for low-frequency component after secondary arc extinguishing is represented in Fig 3.

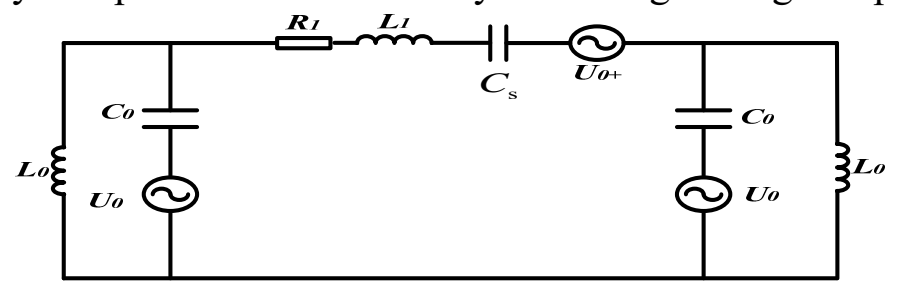

Fig.3. Low frequency equivalent circuit diagram 
Where $U_{0+}$ is the voltage of series capacitor compensation and $U_{0}$ is the voltage of the capacitance to ground resulting from the initial storage of electric charge. According to Laplace transform, the eigenvalue equation can be shown in Equation (1) below:

$$
\left(s^{2} L_{0} C_{0}+1\right)\left[s^{2} L_{0} C_{0} L_{2} C_{z}+s^{2} R_{2} L_{0} C_{0} C_{z}+s^{2}\left(2 C_{z} L_{0}+L_{2} C_{z}+L_{0} C_{0}\right)+s C_{z} R_{2}+1\right]=0
$$

Putting the parameters in Fig.1 into Eq. (1), the eigenvalues can be listed in Table 1:

Table 1 solutions gent equation

\begin{tabular}{ccrr}
\hline $\mathrm{S}=\mathrm{a}+\mathrm{jb}$ & $\mathrm{s} 1, \mathrm{~s} 2$ & $\mathrm{~s} 3, \mathrm{~s} 4$ & $\mathrm{~s} 5, \mathrm{~s} 6$ \\
Extreme point & $-94 \pm \mathrm{j} 2706$ & $-34 \pm \mathrm{j} 82$ & $\pm \mathrm{j} 1408$ \\
\hline
\end{tabular}

Where the real part is the attenuation coefficient of recovery voltage and the imaginary part is the angular frequency. Eigenvalues(s3\&s4) decays slower than others, which is low-frequency component and its frequent $\left(f_{1}\right)$ is $13.06 \mathrm{~Hz}$ 。

In instantaneous earth fault, the fault phase forms a resonance circuit with reactors and capacitors which can generate free oscillation component after secondary arc extinguished.. Based on the second principle of compensation, free-running frequency $\left(f_{2}\right)$ can be calculated as $38.5 \mathrm{~Hz}^{[3]}$.

Due to electromagnetic coupling effect in faulty phase, the recovery voltage also contains power frequency component $\left(f_{2}\right)$ which is $50 \mathrm{~Hz}$.

(2) At single-phase ground fault and secondary arc is not extinguished position, low-frequency component is generated by the oscillation circuit which is formed by residual charges from reactors, capacitors and arc track resistance. Since the fault point exists, Arc will not extinguish. Therefore, there is no free oscillation component. Thus, when the arc current does not extinguish, there are only low-frequency component and power frequency component in the recovery voltage.

\subsection{The characteristic of recovery voltage after series compensation capacitor protection action}

There are two protection actions for series capacitor compensation, which are:

(1) Bypass switch series capacitor compensation: when the energy absorption MOV is saturated, a trigger pulse is send to short the discharge gap and bypass breaker. In another condition, the gap bypass Series Compensation triggered by line protection linkage.

The equivalent circuit of capacitor compensation and MOV shorted by bypass breaker is shown in Fig 4 below:

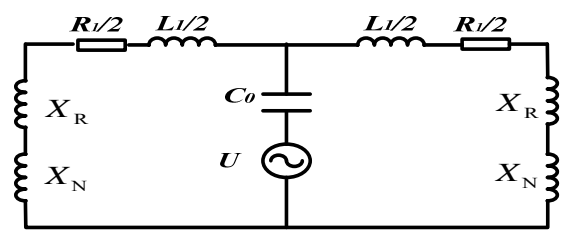

Fig.4. Series compensation is bypass transient fault equivalent circuit diagram

According to Laplace transform, the eigenvalue equation can be shown in Equation (2) below:

$$
\frac{s L_{N}+s L_{F}+\frac{R_{1}}{2}+\frac{s L_{1}}{2}}{2}+\frac{1}{s c_{0}}=0
$$

The Laplace expression of the free oscillation component in recovery voltage is determined in(3): 


$$
s=-\frac{R_{1}}{2\left(L_{1}+2 L_{P}+2 L_{N}\right)} \pm j \frac{\sqrt{\left(4 R_{1}+8 L_{P}+8 L_{N}\right) C-\left(R_{1} C_{1} / 2\right)^{2}}}{\left(L_{1}+2 L_{P}+2 L_{N}\right) C_{0}}
$$

Therefore, $s=-0.345 \pm j 321$. The free oscillation component in recovery voltage $\left(f_{4}\right)$ is $51.11 \mathrm{~Hz}$. When series capacitor compensation is bypassed, low-frequency component is eliminated which is detected by simulation.

(2) When the line fault zone occurs and the current is large, series compensation capacitors are protected by MOV .After breaker tripped, current flows on MOV but bypass switch is not closed. Paper [4]shows that series compensation can be represented by linear resistors and capacitors when MOV is conducting (in Fig. 5).

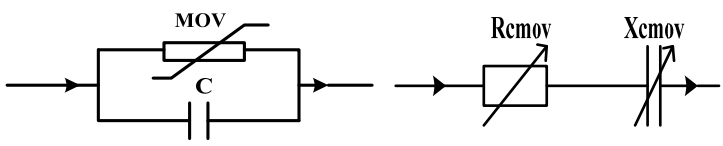
(a) parallel circuit
(b) equivalent circuit

Fig.5. MOV protection operation Series Compensation equivalent circuit

Comparing figure 5 (a) and (b) to be seen, MOV conduction compared with MOV without conduction. The fault phase equivalent circuit is equivalent to only change the line resistance and series compensation capacitor value. In the case of with series compensation capacitor free oscillation frequency calculation is $\omega_{2}=1 / \sqrt{L_{0} C_{0}}$, Series circuit resistance and capacitance values of the impact is not big.

\section{Methods for identifying fault properties}

\subsection{The least squares algorithm model ${ }^{[5]}$}

In order to discriminate fault properties, recovery voltage model is set up as shown in eq. (4):

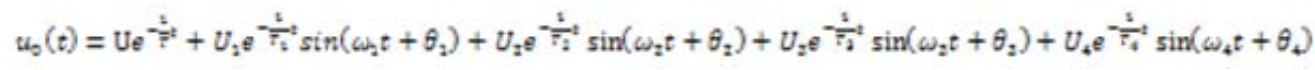

In the formula(4): $t=0$, Circuit breakers on both sides are tripped; $\omega_{1}=2 \pi f_{1} ; \omega_{2}=2 \pi f_{2} ;$ $\omega_{3}=2 \pi f_{3} ; \omega_{4}=2 \pi f_{4} ; u, T$ are the DC component of the amplitude and the decay time constant; $T_{1}$, $\mathrm{T}_{2}, \mathrm{~T}_{3}, \mathrm{~T}_{4}$ are the decay time constant of each component corresponding f1, f2, f3, f4; $\mathrm{u}_{1}, \mathrm{u}_{2}, \mathrm{u}_{3}, \mathrm{u}_{4}$ are amplitude of each component corresponding f1, f2, f3, f4; $\theta_{1}, \theta_{2}, \theta_{3}, \theta_{4}$ are first phase angle of each component corresponding $\mathrm{f} 1, \mathrm{f} 2, \mathrm{f} 3, \mathrm{f} 4$.

In order to facilitate the calculation, $e^{-\frac{1}{T} t}$ can be instead as $1-\frac{t}{T}$. In addition, after the fault phase circuit breaker tripping, Super/UHV line the time constant of free oscillation component and low frequency components is bigger, so $e^{-\frac{1}{T_{2}} t}, e^{-\frac{1}{T_{3}} t}, e^{-\frac{1}{T_{4}} t}$ are approximately taken as 1 . Then, eq. (4) can be simplified to eq.(5).

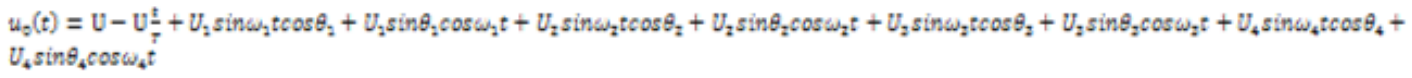

Eq. (5) can be written in matrix form, as shown in eq. (6). 
Which:

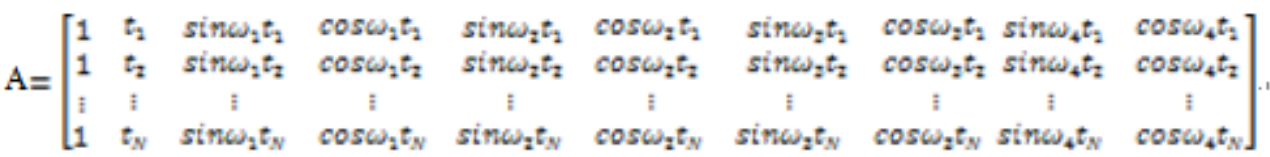

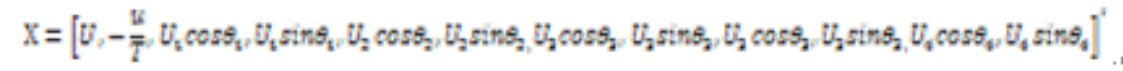

$$
\begin{aligned}
& \mathbf{B}=\left[u_{0}\left(t_{2}\right), u_{0}\left(t_{2}\right), \ldots, u_{0}\left(t_{N}\right)\right]^{*}
\end{aligned}
$$

A is coefficient matrix, can be offline calculation; $X$ is the unknown parameter matrix, it contains 10 parameters, $\mathrm{B}$ is a constant matrix, is sample values of the recovery voltage. Taking $\mathrm{N}$ sampling values of recovery voltage $\mathrm{u}_{0}$ into the eq. (6), can constitute $\mathrm{N}$ equations. Using Least square algorithm solve eq.(6), can obtain the free oscillatory component (i.e. $\left.f_{2}, f_{4}\right)$ we need.

\subsection{Criterion}

From Section 2, in the series capacitor compensation of various conditions, Permanent fault state recovery voltage contain only frequency components and low frequency components; While the recovery voltage of transient fault contained labor frequency components, free oscillatory component and low frequency component. The series compensation protection without action, the frequency of the free oscillation component is $f_{2}$, the $f_{2}$ component amplitude is not 0 ; the series compensation protection action, the frequency of the free oscillation component is $f_{4}$, the $f_{4}$ component amplitude is not 0 .

Using the eq. (6) to calculate the amplitude of $f_{2}, f_{4}$ component: $U_{2}$ and $U_{4}$, if :

$$
\mathrm{U}_{2}=0 \text { and } \mathrm{U}_{4}=0
$$

It is judged as a permanent fault, latching reclosing.if:

$$
\mathrm{U}_{2 \neq 0} \text { or } \mathrm{U}_{4} \neq 0
$$

It is judged as a transient fault, fault phase recloses circuit breaker.

\section{Emulation proof}

Using PSCAD established a circuit simulation model as Figure 1 for simulation. Assumed single-phase ground fault occurred at $300 \mathrm{~ms}$, after $50 \mathrm{~ms}$ the circuit breaker tripped. Transient fault, the secondary arc immediately extinguished; permanent fault, the secondary arc is always present.

In order to verify the applicability criterion, under different circumstances the fault location and fault resistance. Figure 9 shows the $\mathrm{f} 2$ and $\mathrm{f} 4$ components in the instantaneous failure and the free oscillation component in the permanent fault. 

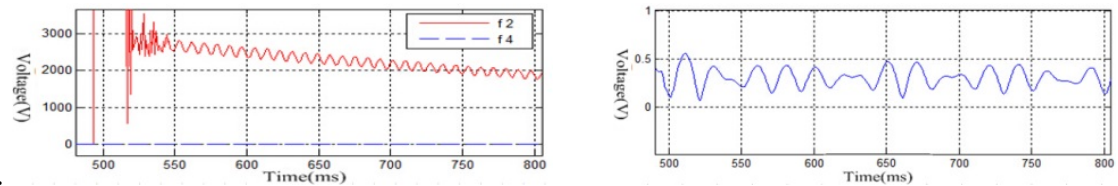

(a) The fault is $0 \mathrm{~km}$ from $\mathrm{M}$ with transition resistance $0.1 \Omega$
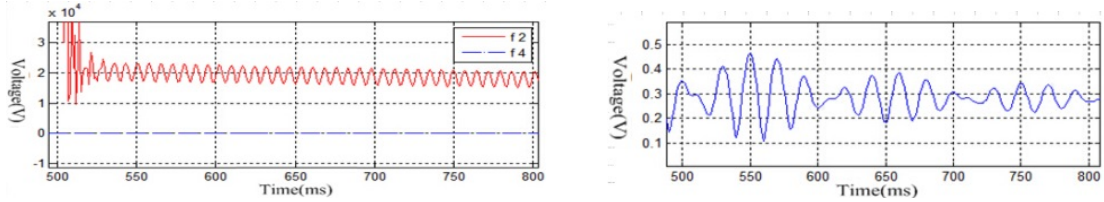

(b) The fault is $0 \mathrm{~km}$ from $\mathrm{M}$ with transition resistance $300 \Omega$
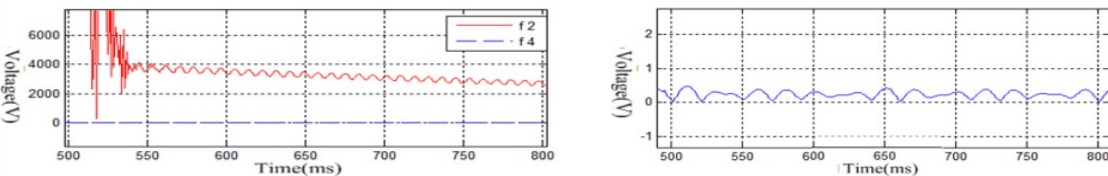

(c) The fault is $75 \mathrm{~km}$ from $\mathrm{M}$ with transition resistance $0.1 \Omega$
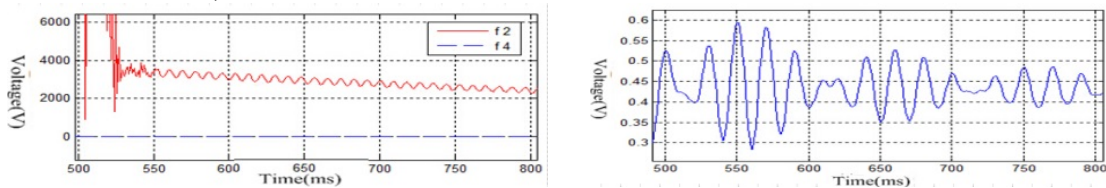

(d) The fault is $75 \mathrm{~km}$ from $\mathrm{M}$ with transition resistance $300 \Omega$
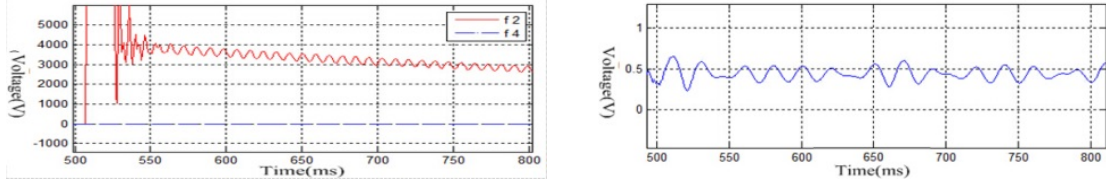

(e) The fault is $150 \mathrm{~km}$ from $\mathrm{M}$ with transition resistance $0.1 \Omega$
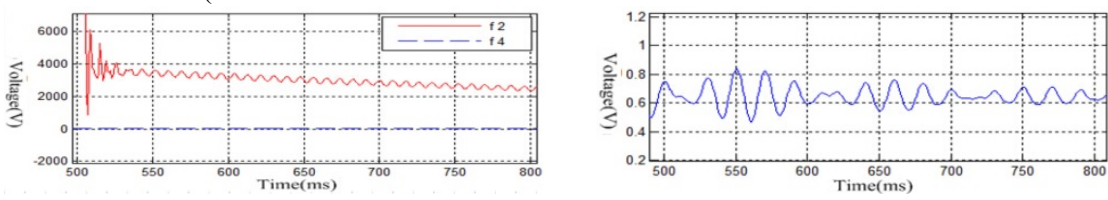

(f) The fault is $150 \mathrm{~km}$ from $\mathrm{M}$ with transition resistance $300 \Omega$

Fig.6 Free oscillation component contrast diagram under different conditions

Table 2 Free oscillation component amplitude

\begin{tabular}{|c|c|c|c|c|c|c|c|c|}
\hline \multicolumn{5}{|c|}{ Series compensation not bypass } & \multicolumn{4}{|c|}{ Series compensated by bypass } \\
\hline $\begin{array}{c}\text { System } \\
\text { operation }\end{array}$ & $\begin{array}{l}\text { Fault location } \\
\text { (distance to } \\
\text { M) }\end{array}$ & $\begin{array}{c}\text { Transition } \\
\text { resistance } \\
(\Omega)\end{array}$ & $\begin{array}{l}\text { Permanent } \\
\text { fault }(\mathbf{V})\end{array}$ & $\begin{array}{l}\text { Transient } \\
\text { fault (V) }\end{array}$ & $\begin{array}{l}\text { Fault location } \\
\text { (distance to } \mathrm{M} \text { ) }\end{array}$ & $\begin{array}{c}\text { Transition } \\
\text { resistance } \\
(\Omega)\end{array}$ & $\begin{array}{l}\text { Permanent } \\
\text { fault (V) }\end{array}$ & $\begin{array}{l}\text { Transient } \\
\text { fault (V) }\end{array}$ \\
\hline \multirow{6}{*}{$\begin{array}{c}\text { Minimum } \\
\text { operating } \\
\text { mode }\end{array}$} & \multirow{2}{*}{$0 \%$} & $\overline{0}$ & 0.0520 & 3702 & \multirow{3}{*}{$0 \%$} & 0 & 4.526 & 3309 \\
\hline & & 300 & 0.1436 & 2669 & & 50 & 0.5876 & 2433 \\
\hline & \multirow{2}{*}{$25 \%$} & 0 & 0.2812 & 2954 & & 300 & 0.2413 & 2487 \\
\hline & & 300 & 0.2743 & 3411 & \multirow{3}{*}{$25 \%$} & 0 & 0.7688 & 6710 \\
\hline & \multirow{2}{*}{$50 \%$} & 0 & 0.3982 & 3638 & & 50 & 0.2935 & 4215 \\
\hline & & 300 & 0.4603 & 3703 & & 300 & 0.4415 & 10350 \\
\hline \multirow{6}{*}{$\begin{array}{l}\text { Maximu } \\
\mathrm{m} \\
\text { operating } \\
\text { mode }\end{array}$} & \multirow{2}{*}{$0 \%$} & 0 & 0.0360 & 2892 & \multirow{6}{*}{$50 \%$} & 0 & 0.4337 & 9932 \\
\hline & & 300 & 0.4325 & 2701 & & 50 & 0.5935 & 10170 \\
\hline & \multirow{2}{*}{$25 \%$} & 0 & 0.1670 & 4993 & & \multirow{4}{*}{300} & \multirow{4}{*}{0.5631} & \multirow{4}{*}{11010} \\
\hline & & 300 & 0.7074 & 3505 & & & & \\
\hline & \multirow{2}{*}{$50 \%$} & 0 & 0.5409 & 4463 & & & & \\
\hline & & 300 & 1.0480 & 3695 & & & & \\
\hline
\end{tabular}


From figure 9 and table 2, With series compensated transmission lines, transient fault occurs when the series capacitor compensation protection is not action, The amplitude of free oscillation components is large; The amplitude of free oscillation is almost 0 , when the permanent fault occurs. See from table 3 in the series compensation capacitor is bypass, Using the eq.(9) decomposes the recovery voltage, free oscillation amplitude component under different nature of the fault is difference, instantaneous failure is far greater than zero, under the permanent fault is about zero. As a result, regardless of whether the action series capacitor compensation protection, in different fault location and the transition resistance, the methods are reliable in judging fault properties in this paper.

\section{Conclusions}

For the line with series capacitor compensation proposed single-phase adaptive reclosure fault nature criterion, the following conclusions can be drawn:

(1) By analyzing the series compensation recovery voltage frequency characteristics under different conditions, recovery voltage include the component of the low-frequency components, free oscillation frequency component and labor component in transient fault; The recovery voltage only include low-frequency components and labor components in the case of a permanent fault.

(2) Under transient fault state, series capacitor compensation if bypassed, free oscillation components at different frequencies.

(3) Recovery voltage free oscillation amplitude component can be Obtained by the least squares algorithm. Whether the use of free oscillation frequency component of 0 discriminant fault properties. A lot of simulation shows the correctness and effectiveness of the method.

\section{References}

[1] LIANG Zhen-feng, SUONAN Jia-le, SONG Guo-bing, et al. Research review of adaptive reclosure in transmission lines[J]. Power System Protection and Control, 2013, 41(6):140-167.

[2] LIU Hao-fang, WANG Zeng-ping, XU Yan, et al.Criterion for determining fault nature in adaptive single-phase reclosing for shunt compensated EHV/UHV transmission lines[J]. Power System Technology, 2006,30(9): 29-34.

[3] NIU Xiao-min, WANG Xiao-tong,SHI, Wei, et al. Secondary arc current and recovery voltage of series compensated transmission line[J].Power System Technology, 1998, 22(9): 9-16. SUONAN

[4] Goldsworthy D L. A linearized model for MOV-protected series capacitors[J].IEEE Transactions on Power Systems, 1987, 2(4): 953-958.

[5] YANG Qi-xun, HUANG Shao-feng. Micro computer relay protection foundation [M], Beijing: China power press, 2007. 